\title{
Aportes y asuntos críticos en la medición de la violencia sexual contra las mujeres en el marco del conflicto armado en Colombia: una reflexión a partir del diseño y los resultados de la Envise 2010-2015*
}

\author{
Contributions and Critical Issues in the Measurement of Sexual \\ Violence Against Women in the Framework of the Armed Conflict \\ in Colombia: A Reflection Based on the Design and Results of \\ the Envise 2010-2015
}

Aportes e assuntos críticos na medição da violência sexual contra as mulheres no marco do conflito armado na Colômbia: uma reflexão a partir do desenho e os resultados da Envise 2010-2015

\author{
Abelardo Carrillo Urrego ${ }^{* *}$ \\ NoElBa Millán CRUZ ${ }^{* * *}$ \\ José Giovany Babativa MÁrqUeZ ${ }^{* \star \star *}$
}

\begin{abstract}
* Este artículo tiene como insumo parte de la información recabada en el marco de la investigación "Violencia sexual contra las mujeres en el marco del conflicto armado en Colombia: prevalencia y procesos de restauración social crítica de las víctimas en un conjunto de municipios con confrontaciones entre la fuerza pública, las guerrillas y las bandas criminales o paramilitares, 2010-2015", financiada por Oxfam Intermón y llevada a cabo por G. O. Sánchez, U. A. Carrillo, G. Babativa, P. Rengifo y L. Silva. (2017). El contenido de este artículo corresponde a la opinión de los autores y no compromete ni necesariamente refleja la opinión de Oxfam Intermón ni de la Casa de la Mujer. El artículo no ha sido presentado como ponencia en ningún congreso o evento académico.

** Sociólogo de la Universidad Nacional de Colombia; magíster en Ciencias Sociales de la Facultad Latinoamericana de Ciencias Sociales (Flacso) - sede académica México; doctor en Ciencias Sociales, Especialidad en Sociología, del Centro de Estudios Sociológicos-El Colegio de México A. C. Profesor asociado de planta, adscrito al Departamento de Ciencias Sociales y Jurídicas de la Universidad del Tolima; integrante del Colectivo de Investigación sobre Conflictos de Género (Ciscog). Correo electrónico: acarrillou@ut.edu.co. ORCID: https://orcid. org/0000-0002-2557-1825

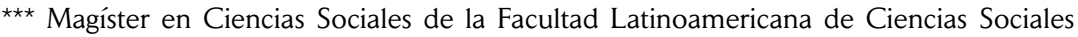
(Flacso) - sede académica México. Profesora asociada, de tiempo completo, adscrita al Departamento de Ciencias Sociales y Jurídicas de la Universidad del Tolima; coordinadora del Colectivo de Investigación sobre Conflictos de Género (Ciscog). Correo electrónico: nmillan@ut.edu.co. ORCID: https://orcid.org/0000-0002-6033-8973

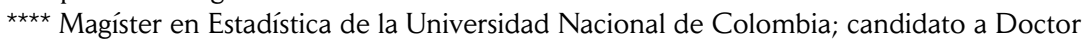
en Análisis Avanzado de Datos Multivariantes y Big Data. Correo electrónico: jgbabativam@ usal.es. ORCID: https://orcid.org/0000-0002-4989-7459
\end{abstract}


Doi: https://doi.org/10.12804/revistas.urosario.edu.co/sociojuridicos/a.7891

Para citar: Carrillo Urrego, A., Millán Cruz, N., \& Babativa Márquez, J. G. (2020). Aportes y asuntos críticos en la medición de la violencia sexual contra las mujeres en el marco del conflicto armado en Colombia: una reflexión a partir del diseño y los resultados de la Envise 2010-2015. Estudios Socio-jurídicos, 22(2), 55-86. Doi: https://doi.org/10.12804/revistas.urosario.edu.co/sociojuridicos/a.7891

\section{RESUMEN}

En este artículo se realiza un análisis crítico de algunos de los resultados más importantes de la Encuesta de Prevalencia de la Violencia Sexual en contra de las mujeres en el contexto del conflicto armado colombiano para el período 2010-2015. Esta encuesta presenta, entre otros aspectos, datos respecto a la magnitud de las diversas conductas vinculadas a la violencia sexual, algunas características sociodemográficas de las víctimas, rasgos de los agresores, los espacios y la frecuencia de tales formas de violencia. Si bien este artículo da cuenta de los aportes de la encuesta para generar información sobre el tema, también plantea un debate en torno a las limitaciones y desafíos que tienen los datos para estimar, entre otros aspectos, la magnitud o prevalencia de la violencia sexual contra las mujeres en el contexto del conflicto armado colombiano. Asimismo, plantea la necesidad de explorar el vínculo entre este tipo de violencia contra las mujeres y el contexto de violencia social e institucional que ha vivido el país en su historia reciente.

Palabras clave: violencia sexual asociada al conflicto, regulación de la vida social, violación, esterilización, conflicto armado.

\section{ABSTRACT}

In this article, the authors present a critical analysis of some of the essential results of the Prevalence Survey of Sexual Violence against women in the context of the Colombian armed conflict for the period 2010-2015. This survey presents, among other aspects, data regarding the magnitude of the different conducts linked to sexual violence, some socio-demographic characteristics of the victims, characteristics of the aggressors, and the spaces and the frequency of such forms of violence. While this article reports on the contributions of the survey to generate information on the subject, it also raises a debate about the limitations and challenges that the data have to estimate, among other aspects, the magnitude or prevalence of sexual violence against women in the context of the Colombian armed conflict. It also raises the need to explore the link between this type of violence against women and the context of social and institutional violence that the country has experienced in its recent history.

Keywords: Conflict-related sexual violence, regulation of social life, violation, sterilization, armed conflict.

\section{RESUMO}

Neste artigo se realiza uma análise crítica de alguns dos resultados mais importantes da Enquete de Prevalência da Violência Sexual contra as mulheres no contexto do conflito armado colombiano para o período 2010-2015. Esta enquete apresenta, entre outros aspetos, dados respeito à magnitude das diversas condutas vinculadas à violência sexual, algumas características sociodemográficas das vítimas, características dos agressores, os espaços e a frequência de tais formas de violência. Ainda que este artigo dá conta dos aportes da enquete para gerar informação sobre o tema, também apresenta um debate 
em torno às limitações e desafios que têm os dados para estimar, entre outros aspetos, a magnitude ou prevalência da violência sexual contra as mulheres no contexto do conflito colombiano. Igualmente, apresenta a necessidade de explorar o vínculo entre este tipo de violência contras as mulheres e o contexto de violência social e institucional que tem vivido o país em sua história recente.

Palavras-chave: violência sexual associada ao conflito, regulação da vida social, estupro, esterilização, conflito armado.

\section{Introducción}

La búsqueda y el uso de datos sobre violencia sexual ${ }^{1}$ contra las mujeres ocurrida en contextos de conflicto armado, tales como el colombiano, han sido definidos como una prioridad por las organizaciones y redes colombianas de mujeres, las/os defensoras/es de derechos humanos, juristas, políticos, instituciones del Estado, periodistas, académicos, etc. Pese a que, en nuestro país, esta forma de violencia ha sido considerada una práctica constante tanto en el conflicto armado como fuera de él, presente en los espacios públicos y privados, los procedimientos para generar información sobre el tema tienen serias limitaciones (Françoise, Guberek \& Hoover, 2011; Oxfam Colombia, 2009; Wood, 2009, 2009a; Casa de la Mujer, 2010; Corporación Humanas, 2009; Corporación Sisma Mujer, 2008).

De un lado, buena parte de las organizaciones y redes de mujeres han documentado la violencia sexual contra las mujeres a partir de relatos o testimonios de sobrevivientes como un intento para identificar posibles patrones. Sin embargo, esta información no permite dar cuenta de la magnitud ni de las características de esta forma de violencia

1 Como punto de partida en este artículo, tenemos en cuenta una precisión conceptual. Se trata de la "distinción entre violencia basada en género y violencia sexual. La violencia basada en género es aquella que se comete contra las personas, sean hombres o mujeres, en razón de su identidad sexual o sus roles de género socialmente construidos. Una de las formas como la violencia basada en género puede manifestarse es la violencia sexual, pero también a través de formas de violencia como el homicidio. Por ejemplo, los feminicidios son una forma de violencia de género extrema en la que mujeres son asesinadas por el hecho de ser mujeres. La violencia sexual es una forma de violencia de género que puede entenderse en un sentido amplio como todo acto de naturaleza sexual que se realiza contra la voluntad de la víctima. Para efectos de este texto, la violencia sexual será entendida como toda conducta objeto de sanción penal que lesiona la integridad sexual de la víctima. Un acto de violencia sexual no necesariamente incluye violencia física, y puede incluso no involucrar el contacto físico, como ocurre con la desnudez forzada" (Centro Nacional de Memoria Histórica, 2015, p. 21; Sánchez, 2010, p. 16). 
contra las mujeres. Los casos incluidos en informes e incluso en la jurisprudencia pueden llegar a ilustrar algunos elementos, pero no pueden ser utilizados para identificar tendencias, patrones, o calcular la posible magnitud del problema. Los casos, relatos o testimonios tienen objetivos y alcances distintos a los que son incluidos o de los que da cuenta una encuesta. En este sentido, realizar una encuesta no solo supone un desafío metodológico, sino que implica costos económicos significativos. En este escenario, poder contar con información recabada a través de una encuesta sobre el tema de la violencia sexual contra las mujeres en escenarios de conflicto supone, de partida, un aporte novedoso al área de conocimiento.

Los datos existentes sobre esta forma de violencia provienen de dos fuentes: el Instituto Nacional de Medicina Legal y Ciencias Forenses (INML) y los resultados de las Encuestas Nacionales de Demografía y Salud (ENDS) de Profamilia. Otra fuente de información sobre el tema a la que es necesario hacer referencia es la reportada por la Unidad para la Atención y Reparación Integral a las Víctimas (UARIV) en el Registro Único de Víctimas (RUV). De acuerdo con esta fuente, durante el período 1985-julio de 2015, se registraron 7.218 casos de delitos contra la libertad y la integridad sexual, siendo las mujeres las principales víctimas $(89,7 \%)$.

No obstante, "no existen datos robustos, confiables y válidos sobre la magnitud de la violencia sexual en el marco del conflicto" (Centro Nacional de Memoria Histórica, 2017, p. 472; Centro Nacional de Memoria Histórica, 2015, p. 469). Asimismo, buena parte de los estudios consultados coinciden en señalar que con la información reportada por este conjunto de fuentes:

Resulta bastante difícil detectar casos de violencia sexual específicamente relacionados con el conflicto armado. Si de manera preliminar consideramos "relacionados con el conflicto" todos aquellos casos en que se mencionan actores armados como responsables, identificamos sólo una pequeña porción. ${ }^{2}$ Las organizaciones y redes de mujeres generalmente no adoptan esta definición al elaborar y presentar sus 
reportes sobre la violencia sexual relacionada con el conflicto armado (Françoise, et al., 2011, p. 52; Centro Nacional de Memoria Histórica, 2015, p. 75).

Según Françoise et al. (2011): "La información reportada por estas fuentes tiene dos limitaciones importantes. De un lado, los datos son usados, generalmente, sin un análisis detallado de su cobertura y la información sobre violencia sexual que suministran se refiere, en su mayoría, a violencia intrafamiliar y no a casos relacionados con el conflicto armado" (p. 32).

En un esfuerzo por superar estas limitaciones en la información y en los procedimientos para recabarla, la Casa de la Mujer -con el apoyo de Oxfam Intermón - realizó, durante el año 2016, la Encuesta de Prevalencia de Violencia Sexual contra las Mujeres en el Marco del Conflicto Armado Colombiano (Envise 2010-2015). En este artículo se presentan algunos de los principales hallazgos de esta encuesta, no publicados y de nuestra autoría, y se plantea un debate en torno a las limitaciones y desafíos que tiene la información que suministra para documentar esta forma de violencia contra las mujeres. En la primera parte, se expone la estrategia metodológica y los criterios éticos a partir de los cuales se realizó la encuesta. En la segunda parte, se describen los aportes de la encuesta al dar cuenta del conocimiento que ellas tenían respecto a las formas de violencia contra las mujeres que se presentan en el municipio, localidad o comuna donde residen. En la tercera parte, se mencionan los datos respecto al conocimiento que las informantes tenían de los hechos de violencia sexual en los que las víctimas correspondían a familiares, amigas, compañeras o vecinas. Enseguida, se ofrecen las estimaciones de la violencia sexual a partir de aquellos casos en los que las encuestadas eran las víctimas directas. En este apartado se lleva a cabo una caracterización de estas últimas, de los agresores, de los espacios, de la frecuencia y de las características de los diferentes tipos de violencia sexual. Para terminar, se realiza una discusión a partir de los resultados y se brinda un conjunto de consideraciones finales.

(militares, policías, organizaciones paramilitares bajo el mando directo de otros actores estatales) y no estatales (organizaciones y milicias rebeldes)" (p. 16). 


\section{Aspectos metodológicos y éticos}

La encuesta efectuada buscaba dar cuenta de la magnitud de las diversas "conductas vinculadas a la violencia sexual contra las mujeres en el marco del conflicto armado para el período 2010-2015, en un conjunto de municipios con confrontaciones entre la fuerza pública, las guerrillas y las bandas criminales o paramilitares" (Casa de la Mujer, 2017). Entre otros aspectos, la encuesta pretendía ofrecer información para visibilizar a las víctimas, caracterizar a los agresores, los espacios y la frecuencia de los diferentes tipos de violencia sexual en contra de las mujeres entre 15 y 44 años de edad. Para lograr este objetivo, se llevaron a cabo ejercicios comparativos de los resultados según algunas características sociodemográficas relevantes de las encuestadas, tales como la posición socioeconómica, la edad y el origen étnico racial (Casa de la Mujer, 2017).

El marco muestral se definió a partir de la revisión de 73 informes de alertas tempranas o informes de riesgo ${ }^{3}$ publicados por la Defensoría del Pueblo en el período de referencia (2010-2015). Dicha información se contrastó y consolidó con la base de datos elaborada por el Centro de Recursos para el Análisis de Conflictos (Cerac), construida a partir de datos sobre presencia de grupos armados del conflicto interno y número de eventos del conflicto en municipios de Colombia. De este conjunto de datos se consolidó un total de 142 municipios distribuidos de forma muy asimétrica en los 29 departamentos que integran al país.

Para estimar el tamaño de la muestra, se consideró una prevalencia del $50 \%$ y un error de muestreo del $5 \%$, con lo que el tamaño de la muestra fue de 1954. Asimismo, el diseño muestral se realizó para dar estimaciones con niveles de confianza del $95 \%$ y precisión que garantiza errores de muestreo menores al 6\% a nivel total (Casa de la Mujer, 2017).

Problemas de seguridad relacionados con acciones de violencia común y de violencia política hicieron necesario, en primer lugar, aplicar

3 Para identificar y valorar las situaciones del riesgo, es útil toda la información sobre manifestaciones de conflicto armado: amenazas o hechos que configuran peligros para la población civil, factores de vulnerabilidad de las comunidades y mecanismos sociales e institucionales que contribuyen a la protección de la población (Defensoría del Pueblo, 2010; Otero, Quintero \& Bolivar, 2009). 
la encuesta únicamente en las cabeceras municipales; y, en segundo lugar, reemplazar algunos de los municipios seleccionados inicialmente. Aplicar la encuesta en las cabeceras municipales plantea dificultades para garantizar que los resultados de esta sean representativos para la totalidad de las mujeres que residen en los municipios incluidos en el marco muestral.

Conforme con la Casa de la Mujer (2017), "desde el punto de vista teórico, el enfoque de investigación se enmarcó en la teoría feminista, ${ }^{4}$ por ende, en la comprensión de las violencias en contra de las mujeres como un contínuum en sus vidas y no como expresiones inconexas de rabia o pérdida de control de los varones" (p. 13).

De ahí que se consideró la violencia sexual en sus múltiples expresiones, y no solamente como violación o acoso sexual. Para Wood (2016), "la violencia sexual es una categoría más amplia que incluye violación, asalto sexual no penetrativo, mutilación sexual, esclavitud sexual, prostitución forzada y embarazo forzoso" (p. 25). Por ello, para la encuesta se amplió el espectro de las violencias y se incluyeron algunas tipificadas por el Código Penal colombiano y otras que aún no lo están, como la regulación de la vida social (Casa de la Mujer, 2017, p. 13).

1) La violación es entendida como el "acto de forzar a tener relaciones o contactos sexuales a otra persona, amenazando con mecanismos de violencia o empleándolos (desde la violencia física hasta la psicológica, pasando por la simbólica)" (Slaughter, 2009, p. 64).

2) La prostitución forzada es entendida como:

La acción o el conjunto de acciones realizadas por una persona o por grupos que tienen como finalidad la obtención por imposición de servicios sexuales, a través de amenazas u otras formas de violencia, a cambio de las cuales la víctima o generalmente quien la controla recibe beneficios monetarios. En ella se incluye la categoría de la esclavitud sexual forzada que supone la disponibilidad del cuerpo de las mujeres

4 Este tipo de análisis intenta explicar e interpretar las violencias en contra de las mujeres como expresión de las relaciones de opresión, subordinación e injusticia social que estas viven y como dispositivos de poder que utiliza el sistema sociosexual patriarcal para mantener, recrear y reproducir dichas relaciones. 
para su uso sexual y en donde las costumbres sociales y la protección legal que normalmente limitarían las acciones de un propietario de esclavos dejan de tener efecto en este contexto (Sanchis, 2011, p. 917).

3) El embarazo forzado es entendido como "una acción de control sobre una mujer embarazada, cuya pretensión de dominio busca asegurarse la continuación de su embarazo o el nacimiento de su hija-o en contra de la voluntad de la madre; este embarazo puede ser el resultado de una violación, pero no siempre ésta es la causa. De igual manera, en muchas ocasiones este intento de control incluye el confinamiento ilícito de la mujer embarazada" (Casa de la Mujer, 2017, p. 13).

4) El aborto forzado constituye el cuarto tipo de violencia sexual. Este ha sido definido como "el acto o el conjunto de acciones que tienen como finalidad la interrupción inducida de un embarazo contra la voluntad de la mujer en embarazo" (Echeverri, 2002, p. 57).

5) La esterilización forzada, el quinto tipo de violencia sexual, ha sido considerada como "la acción de planificación reproductiva producto de la obligación no consentida de la persona afectada" (Casa de la Mujer, 2017, p. 14).

6) El acoso sexual fue entendido como "cualquier presión o insinuación no deseada por la persona que lo recibe y que busca la satisfacción de deseos sexuales por quien la ejerce. Es claro pues que el acoso sexual puede darse a través de propuestas, ofensas, gestos obscenos o comentarios sexuales" (Fileborn, 2013, p. 10).

7) Los servicios domésticos forzados han sido definidos como "la acción o conjunto de acciones mediante las cuales generalmente un grupo (aunque también puede ser una persona) que detenta el poder, obliga a una mujer a realizar para ellos labores domésticas que pueden trascender a actos sexuales" (Casa de la Mujer, 2017, p. 14).

8) La regulación de la vida social se entendió como "el acto o el conjunto de actos por los cuales, mediante el uso de la fuerza o amenaza de usarla, se busca establecer patrones de comportamiento y conducta social. Entre las principales formas de regulación de la vida social se encuentran el control de la sexualidad, la regulación de la forma de vestirse y la regulación de la vida afectiva" (Echeverri, 2002, p. 57). 
Para la realización de la encuesta, se atendieron con estricta rigurosidad "las recomendaciones para el abordaje de las cuestiones éticas y de seguridad en la investigación sobre la violencia basada en el género publicadas por la Organización Mundial de la Salud (OMS)" (World Health Organization, 1999; Valdez, 2004, p. 428). De acuerdo con González y Valdez (2008):

Se reconoce que hay aspectos de la investigación sobre la violencia sexual que trascienden a la que se realiza sobre otros temas debido a la naturaleza potencialmente amenazante y traumática del asunto. En el caso de la violencia sexual, la seguridad y hasta la vida de las mujeres encuestadas y de las encuestadoras podían correr peligro. Por esta razón la encuesta tuvo en cuenta los siguientes imperativos éticos: 1) garantizar la seguridad de encuestadas y encuestadoras, aspecto que está muy ligado a la necesidad de garantizar la privacidad/confidencialidad a la hora de la aplicación de la encuesta; 2 ) asegurar que las personas que asumirían el rol de encuestadoras tuviesen una capacitación específica a fin de que estuviesen en condiciones de contener adecuadamente el impacto emocional que las mujeres pudiesen tener al hablar de la violencia que sufrieron en el pasado o que viven en el presente; y 3 ) proveer a las encuestadas información acerca de los centros de atención a los que pudiesen recurrir (p. 438).

\section{Resultados}

\section{Conocimiento de las participantes respecto a las formas de violencia contra las mujeres que se presentan en el municipio, localidad o comuna donde residen}

En cuanto al conocimiento que las encuestadas tenían respecto a las formas de violencia contra las mujeres que se presentan en su municipio, localidad o comuna, el $54 \%$ manifestó la violencia física; el 52,6\%, violencia psicológica; el $41 \%$, amenazas; el $40 \%$, control o prohibición; el $27 \%$, violencia sexual; y el 25,6\%, asesinato. Es importante precisar, tal como se puede observar en la tabla 1 , que los porcentajes se exponen 
de esta forma en la medida en que una mujer encuestada pudo haber mencionado dos o más formas de violencia al contestar esta pregunta.

Al profundizar en cada una de estas modalidades de violencia, se encontró que las formas en que se manifiesta el maltrato físico fueron las siguientes: al 88,2\% las han golpeado con la mano, al 81,6\% las han empujado/zarandeado, al 57,4\% las han pateado o arrastrado, al $51 \%$ las han golpeado con algún objeto, al 37,5\% las han amenazado con un arma, al 33,6\% las han atacado con un arma y al 25,8\% las han tratado de estrangular o quemar. Asimismo, al indagar por los actores que propiciaron estos hechos, se halló que fueron, en su orden: familiares de la víctima, con el 63,4\%; otros no familiares de la víctima, con el 38\%; otros actores no determinados, con el 9,2\%; actores armados ilegales, con el 5,6\%; y la fuerza pública, con el 3,4\%.

Tabla 1. Conocimiento de las encuestadas respecto a las formas de violencia contra las mujeres que se presentan en el municipio, localidad o comuna donde residen

\begin{tabular}{|c|c|c|}
\hline & & Total \\
\hline \multirow{4}{*}{ Control o prohibición } & Sí & $40,19 \%$ \\
\hline & No & $59,35 \%$ \\
\hline & Sin información & $0,46 \%$ \\
\hline & Total (universo representado) & 4767023 \\
\hline \multirow{4}{*}{ Amenazas } & Sí & $40,91 \%$ \\
\hline & No & $58,64 \%$ \\
\hline & Sin información & $0,45 \%$ \\
\hline & Total (universo representado) & 4767023 \\
\hline \multirow{4}{*}{ Violencia psicológica } & Sí & $52,64 \%$ \\
\hline & No & $47,20 \%$ \\
\hline & Sin información & $0,16 \%$ \\
\hline & Total (universo representado) & 4767023 \\
\hline \multirow{4}{*}{ Violencia física } & Sí & $54,01 \%$ \\
\hline & No & $45,86 \%$ \\
\hline & Sin información & $0,13 \%$ \\
\hline & Total (universo representado) & 4767023 \\
\hline
\end{tabular}




\begin{tabular}{|c|c|c|}
\hline & & Total \\
\hline \multirow{4}{*}{ Violencia sexual } & Sí & $27,19 \%$ \\
\hline & No & $71,64 \%$ \\
\hline & Sin información & $1,17 \%$ \\
\hline & Total (universo representado) & 4767023 \\
\hline \multirow{4}{*}{ Asesinato } & Sí & $25,64 \%$ \\
\hline & No & $73,67 \%$ \\
\hline & Sin información & $0,70 \%$ \\
\hline & Total (universo representado) & 4767023 \\
\hline
\end{tabular}

Base: total 142 municipios en conflicto

Nota: resultados válidos para hacer inferencias para los 142 municipios del marco muestral.

Fuente: elaboración de los autores con base en los resultados de la encuesta Envise Colombia 2010-2015.

Pese a que la modalidad de violencia psicológica no se desagregó en sus diversas manifestaciones, los actores que la propiciaron fueron, en su orden: los familiares de la víctima, con el 61,9\%; otros no familiares de la víctima, con el 36,8\%; otros actores no determinados, con el 7,7\%; y los actores armados ilegales, con el 5,3\%. En la modalidad de violencia contra las mujeres vinculada a las amenazas, las formas en que se manifestaron fueron las siguientes: las han amenazado con quitarle la vida, con el 70\%; las han amenazado con quitarles las/os hijas/os, con el 62\%; las han amenazado con quitarle la vida a alguno de sus familiares, con el 40\%; las han amenazado con expulsarlas del pueblo, con el $34 \%$; las han amenazado con quitarle la vida a su novio o pareja, con el 32,2\%; y las han amenazado con violarlas a ellas o a sus hijas, con el 22,3\%. Respecto a los actores que propiciaron estos hechos, fueron, en su orden: otros no familiares, con el $45 \%$; familiares de la víctima, con el 44,7\%; otros actores no determinados, con el 13,9\%; actores armados ilegales, con el 9,3\%; y la fuerza pública, con el 3,4\%.

Las maneras en que se manifestó la violencia contra las mujeres vinculada al control o la prohibición fueron las siguientes: les han impedido contactar amigos, con el 70,6\%; les han impedido salir a la calle con amigos o con el novio, con el 68\%; les han restringido las horas en las que pueden salir a la calle, con un $66,8 \%$; sienten que las vigilan, 
con el 60,8\%; y les han cuestionado y obligado a cambiar el modo de vestirse, con el 53\%. El 65,3\% de los actores que propiciaron estos hechos fueron familiares de la víctima; el 29,2\%, otros no familiares; el $11 \%$, otros actores no determinados; y el 8,3\%, actores armados ilegales.

La violencia sexual se manifestó de las siguientes formas: al 71,1\% las han acosado sexualmente, al 65,3\% las han obligado a tener relaciones sexuales sin su consentimiento, al 62,5\% las han tocado o manoseado sin su consentimiento, al 37\% las han obligado a desnudarse, al 33,7\% las han obligado a abortar, al 21,6\% las han obligado a prostituirse y al $18,8 \%$ las han obligado a practicarse la esterilización. En cuanto a los actores que propiciaron estos hechos, fueron, en su orden: familiares de la víctima, con el 48\%; otros no familiares de la víctima, con el 44,5\%; otros actores no determinados, con el 16,8\%; actores armados ilegales, con el 3,2\%; y la fuerza pública, con el 4,3\%. En la modalidad de asesinato, los actores que propiciaron los hechos fueron, en su orden: familiares de la víctima, con el 36,6\%; otros actores no determinados, con el 30\%; otros no familiares de la víctima, con el 29,8\%; actores armados ilegales, con el 18,4\%; y la fuerza pública, con el $3 \%$.

$\mathrm{Al}$ indagar, con más detalle, respecto a cuáles de los actores armados ilegales propiciaron los hechos de violencia contra las mujeres en todas las modalidades a las que ya se ha hecho mención, el $70 \%$ de las encuestadas manifestó que las bandas criminales emergentes. Pese a esto, el 26,2\% expresó no saber ni respondió a la misma pregunta. Por otra parte, el $42 \%$ de las encuestadas dijo que los grupos guerrilleros fueron los responsables de los hechos, aunque el 51,6\% declaró no saber ni respondió a la misma pregunta. Asimismo, al indagar, con más detalle, respecto a cuáles de los actores pertenecientes a la fuerza pública propiciaron los hechos de violencia contra las mujeres en todas las modalidades a las que ya se ha hecho mención, el 65,3\% señaló que la policía. Sin embargo, el $27 \%$ indicó no saber ni respondió a la misma pregunta. Por otra parte, el 44,2\% de las encuestadas apuntó que el ejército. No obstante, el $35 \%$ de las encuestadas manifestó no saber ni responder a la misma pregunta.

En síntesis, estos datos pueden brindarnos evidencia respecto a la magnitud y las características de la violencia contra las mujeres que se presenta en los ámbitos locales. Así, llama la atención que, con excepción 
de la violencia vinculada a las amenazas, en todas las demás formas de violencia los familiares de la víctima son reportados como los principales agresores. Esto último sugiere que lo mencionado por las encuestadas puede corresponder, en buena medida, a eventos de violencia intrafamiliar. Igualmente, y pese a la baja participación de los actores armados ilegales como principales agresores, es relevante lo mencionado respecto a una creciente participación de las bandas criminales emergentes.

No obstante, un aspecto que puede representar una dificultad importante en cuanto a los datos expuestos en este apartado y de la lectura que pueda hacerse de ellos está vinculado a que la herramienta utilizada para la captura de la información no podía evitar (filtrar o controlar) que el conocimiento en torno al cual se referían las mujeres encuestadas estuviera vinculado a aquel que hubiesen visto en los medios de comunicación o por terceras personas, sino de aquellos casos conocidos de primera mano. Del mismo modo, el cuestionario y el operativo de campo no permitieron evitar que las encuestadas se estuviesen refiriendo a un mismo caso. Esto último representa una limitación y un desafío en la medida en que se puede incurrir en una sobreestimación (por los reportes múltiples no detectados de los mismos eventos) tanto de las formas de violencia como de los agresores.

\section{Conocimiento de hechos de violencia sexual contra mujeres en el entorno más cercano de las encuestadas}

Tal como puede observarse en la tabla 2, el 25,4\% de las encuestadas dijo tener conocimiento respecto a los hechos de violencia sexual contra alguna de sus amigas, compañeras, vecinas o familiares que viven en el municipio, durante los años 2010-2015. Al indagar con más detalle en torno a la forma de violencia de la que fueron víctimas, el $23,7 \%$ expresó que fue de regulación de la vida social; el 21,5\%, de acoso sexual; el 14,5\%, de violación; el 10,6\%, de aborto forzado; el $8 \%$, de servicios domésticos forzados; el $4,5 \%$, de prostitución forzada; el 3,8\%, de embarazo forzado; y el 2,4\%, de esterilización forzada. En cuanto a los actores que propiciaron la forma de violencia vinculada a la regulación de la vida social, se identificó que el 66\% correspondía a un familiar de la víctima; el 35,6\%, a un no familiar de la víctima; el 
$11 \%$, a un actor armado ilegal; el 5,4\%, a otro actor no determinado; y el 2,2\%, a la fuerza pública. Asimismo, al preguntar por el lugar donde se presentó esta forma de violencia, el $64,6 \%$ de las mujeres señaló que sucedió en el espacio privado y el 43,6\%, en el espacio público.

Tabla 2. Conocimiento de las encuestadas respecto a alguna amiga, compañera, vecina o familiar que ha sido víctima de violencia sexual en el municipio en el período 2010-2015

\begin{tabular}{|l|c|c|c|}
\hline & Síha sido víctima & No ha sido víctima & Total \\
\hline Sí & $43,85 \%$ & $21,36 \%$ & $25,49 \%$ \\
\hline No & $52,29 \%$ & $76,23 \%$ & $71,83 \%$ \\
\hline NS/NR & $3,73 \%$ & $2,17 \%$ & $2,46 \%$ \\
\hline Sin información & $0,14 \%$ & $0,24 \%$ & $0,22 \%$ \\
\hline Total (universo representado) & 875437 & 3891586 & 4767023 \\
\hline
\end{tabular}

Base: total 142 municipios en conflicto

Nota: resultados válidos para hacer inferencias para los 142 municipios del marco muestral.

Fuente: elaboración de los autores con base en los resultados de la encuesta Envise Colombia 2010-2015.

Por otra parte, al hacer esta misma indagación para los actores que cometieron la forma de violencia vinculada a los servicios domésticos forzados, se identificó que el $65 \%$ fue un familiar de la víctima; el $37 \%$, un no familiar de la víctima; el 8,4\%, un actor no determinado; el 7,1 \%, un actor armado ilegal; y el $3 \%$, la fuerza pública. En cuanto al lugar donde se presentó dicha forma de violencia, el 82,3\% de las mujeres encuestadas indicó que fue en el espacio privado y el 22,2\%, en el espacio público. Para la forma de violencia vinculada al acoso sexual, se identificó que el 57,2\% la ejecutó un no familiar de la víctima; el $34 \%$, un familiar de la víctima; el 16,5\%, un actor no determinado; el $11,7 \%$, un actor armado ilegal; y el $4 \%$, la fuerza pública. Respecto al lugar donde se presentó esta forma de violencia, el 41,4\% manifestó que fue en el espacio público y el 33,8\%, en el espacio privado o doméstico.

En el caso de la forma de violencia vinculada a la esterilización forzada, se estableció que el 59,5\% la ejerció un familiar de la víctima; el $42 \%$, un no familiar de la víctima; el $19,8 \%$, otro actor no determinado; el 10,6\%, un actor armado ilegal; y el 6,8\%, la fuerza pública. El 5,7\% 
de las encuestadas declaró que esta forma de violencia se presenta en el espacio privado y el 3,7\%, en el espacio público. Para la forma de violencia vinculada al embarazo forzado, se determinó que el 56,2\% la llevó a cabo un familiar de la víctima; el $40 \%$, un no familiar de la víctima; el $17 \%$, otro actor no determinado; el 13,9\%, un actor armado ilegal; y el 9,6\%, la fuerza pública. El 62\% de las mujeres encuestadas apuntó que tal forma de violencia se presentó en el espacio privado o doméstico y el 33,5\%, en el espacio público. En cuanto al aborto forzado, el 72,2\% fue un familiar de la víctima; el 31,2\%, un no familiar de la víctima; el 9\%, otro actor no determinado; el 3,7\%, un actor armado ilegal; y el 2,9\%, la fuerza pública. El 73,7\% de las mujeres encuestadas informó que esta forma de violencia se presentó en el espacio privado y el 19,6\%, en el espacio público.

$\mathrm{Al}$ analizar la prostitución forzada, el $51 \%$ de los agresores fue un familiar de la víctima; el $42 \%$, un no familiar de la víctima; el 16\%, otro actor no determinado; el 18\%, un actor armado ilegal; y el 3,7\%, la fuerza pública. El 56\% de las mujeres encuestadas notificó que esta forma de violencia se presentó en el espacio privado o doméstico y el 50,3\%, en el espacio público. En cuanto a la violación, el 50\% de los agresores fue un no familiar de la víctima; el 42,2\%, un familiar; el $15,8 \%$, otro actor no determinado; el 2,8\%, un actor armado ilegal; y el 4,3\%, la fuerza pública. El $60,8 \%$ de las mujeres encuestadas manifestó que esta forma de violencia se presentó en el espacio privado y el 43,7\%, en el espacio público.

Al observar de forma detallada los datos respecto a los actores armados ilegales que propiciaron los hechos de violencia contra las mujeres (en todas las modalidades a las que ya se ha hecho mención aquí), encontramos que el $64,4 \%$ de las encuestadas dijo que correspondían a las bandas criminales emergentes. Pese a esto, el 28,2\% señaló no saber ni respondió a la misma pregunta. El 23\% de las encuestadas indicó que los grupos guerrilleros fueron los responsables de los hechos, aunque el 67,3\% expresó no saber ni respondió a la misma pregunta. Asimismo, al indagar respecto a cuáles de los actores pertenecientes a la fuerza pública propiciaron los hechos de violencia mencionados, el $56,8 \%$ declaró que la policía y el 29,3 \% señaló al ejército. No obstante, el 15,3\% apuntó no saber ni respondió a la misma pregunta. 
Desde el punto de vista de González y Valdez (2008):

Un aporte importante de esta encuesta es que asumió una perspectiva que buscaba superar la conceptualización de las mujeres como "víctimas" exclusivamente para tomar en cuenta que también son agentes activos que recurren a los medios a su alcance para tratar de modificar condiciones que les son desfavorables y opresivas. Por esta razón, además de medir la prevalencia de las diversas formas de violencia sexual que sufrieron, la encuesta averiguó en qué medida las mujeres que han sido objeto de maltrato lo han manifestado al personal de salud y/o han recurrido a las autoridades judiciales en búsqueda de apoyo (p. 440).

El análisis de la información sobre esta última cuestión arrojó resultados importantes: al preguntarle a las encuestadas respecto a si las víctimas habían denunciado los hechos de violencia en todas las modalidades mencionadas aquí, el 20,3\% manifestó que lo hizo; el 65\%, que no lo hizo; y el 13,7\% no respondió la pregunta. El 52,6\% de las encuestadas informó que la víctima hizo la denuncia en una sola oportunidad. El $23 \%$ notificó que la víctima hizo la denuncia en dos oportunidades y el $23 \%$ lo hizo en tres oportunidades.

En síntesis, esta información nos ofrece evidencia de la magnitud y de las características de los hechos de violencia sexual de los que fueron víctimas amigas, compañeras, vecinas o familiares de las mujeres encuestadas. Llama la atención que los tipos de violencia más frecuentes fuesen la regulación de la vida social, el acoso sexual y la violación, y que, con excepción del acoso, los familiares de la víctima hayan sido, nuevamente, los principales agresores. Esto es corroborado por la información, según la cual el lugar donde se presentaron los hechos fue el ámbito privado o doméstico. Adicionalmente, estos datos vuelven a sugerir que lo mencionado por las encuestadas corresponde, en buena medida, a eventos de violencia intrafamiliar y no a eventos relacionados con el conflicto armado. Sin embargo, en la medida en que se les indagó a las encuestadas respecto a mujeres más cercanas en el apartado anterior, pudo haberse evitado el registro repetido de casos y, por lo tanto, la sobreestimación de la violencia sexual.

Del mismo modo, pese a la baja participación de los actores armados ilegales como principales agresores, es importante lo encontrado 
en la información respecto a una creciente participación de las bandas criminales emergentes. Son relevantes los datos respecto a si las personas cercanas a la entrevistada habían denunciado o no los hechos de violencia sexual en la medida en que puede estar dando cuenta, entre otros aspectos, de las dificultades o desafíos que tienen las mujeres para acceder a la justicia y de la poca o nula confianza en las instituciones.

\section{Violencia sexual cuyas víctimas directas fueron las encuestadas}

En este apartado se ofrecen algunos de los resultados de la encuesta relacionados con las formas de violencia sexual de las cuales las encuestadas manifestaron ser las víctimas directas. Estos resultados fueron los que permitieron estimar el número total de mujeres entre 15 y 44 años violentadas sexualmente durante el período 2010-2015 y que residen en municipios donde hay presencia de actores armados ilegales. ${ }^{5} \mathrm{Tal}$ como se puede observar en la tabla 3:

La encuesta muestra la prevalencia ${ }^{6}$ de $18,36 \%$ para los $142 \mathrm{mu}^{-}$ nicipios con presencia de fuerza pública, guerrilla y paramilitares o Bacrim. De esta prevalencia se desprende que, durante los seis años tomados como referencia, 875437 mujeres fueron víctimas directas de algún tipo de violencia sexual. Este dato representa que anualmente, en promedio, 145906 mujeres fueron víctimas directas de algún tipo de violencia sexual, 12158 lo fueron cada mes, 400 lo fueron cada día y 16, cada hora (Casa de la Mujer, 2017, p. 5).

5 La categoría actores armados ilegales hace referencia en esta investigación a paramilitares (incluyendo los grupos que tras la desmovilización se conocen como nuevas bandas emergentes) y guerrillas (FARC y ELN). El ELN es el Ejército de Liberación Nacional.

6 La Casa de la Mujer (2017) afirma: "El dato de prevalencia se construye con el número de mujeres en el rango de edad, que han sido afectadas por lo menos una vez durante el período 2010-2015 por alguna forma de violencia sexual, entre el número total de mujeres en el rango de edad que pueden ser afectadas por este fenómeno durante el período establecido. Teniendo en cuenta que no existen proyecciones oficiales desagregadas por sexo, grupos de edad y áreas (en este caso para la cabecera municipal) para el año 2016, el muestreo probabilístico permitió estimar el número total de mujeres en el rango de edad que residen en los 142 municipios que conforman el universo objeto de estudio (para este caso, población en cabecera) para el año 2016. Este dato se tomó para el cálculo de la prevalencia, teniendo en cuenta que es un dato confiable y muy cercano al año de interés" (p. 16). 
Tabla 3. Prevalencia de mujeres víctimas de violencia sexual en los 142 municipios representados en el marco muestral de la Envise

\begin{tabular}{|l|c|}
\hline & Total \\
\hline Sí & $18,36 \%$ \\
\hline No & $81,64 \%$ \\
\hline Total (universo representado) & 4767023 \\
\hline
\end{tabular}

Base: total 142 municipios en conflicto

Nota: resultados válidos para hacer inferencias a los 142 municipios del marco muestral. Fuente: encuesta Envise Colombia 2010-2015.

Ahora bien, el análisis de la prevalencia de mujeres víctimas a nivel municipal arroja los siguientes resultados. Al aplicar una prueba de hipótesis de proporciones bilateral (o de dos caras) con un nivel de significación de 0,05 (nivel de confianza del 95\%), hallamos que las tasas de prevalencia de violencia sexual contra las mujeres de los municipios de Medellín, Buenaventura y Bogotá son más altas que para el resto de municipios incluidos en la muestra. Tal como lo ilustran las tablas 4 y 5, llama la atención que la tasa de prevalencia de estos municipios supere la calculada para el universo de mujeres incluidas en la encuesta.

Sin embargo, al analizar la prevalencia de la violencia sexual contra las mujeres según el tamaño de los municipios podemos observar que la proporción de mujeres víctimas de violencia sexual es mayor en los municipios pequeños o con menos de 35000 mujeres que en las ciudades principales, intermedias y municipios medianos. En otros términos, las mujeres que residen en municipios pequeños se encuentran en mayor riesgo de ser víctimas de violencia sexual (Casa de la Mujer, 2017, p. 38).

Esta información nos permite establecer que la distribución de los fenómenos sociales en el territorio de un país no es homogénea y la violencia sexual contra las mujeres no es la excepción. Las causas detrás de estas diferencias constituyen una pregunta de investigación relevante y se han planteado algunas hipótesis interesantes. El Centro Nacional de Memoria Histórica (2015) ha señalado que 


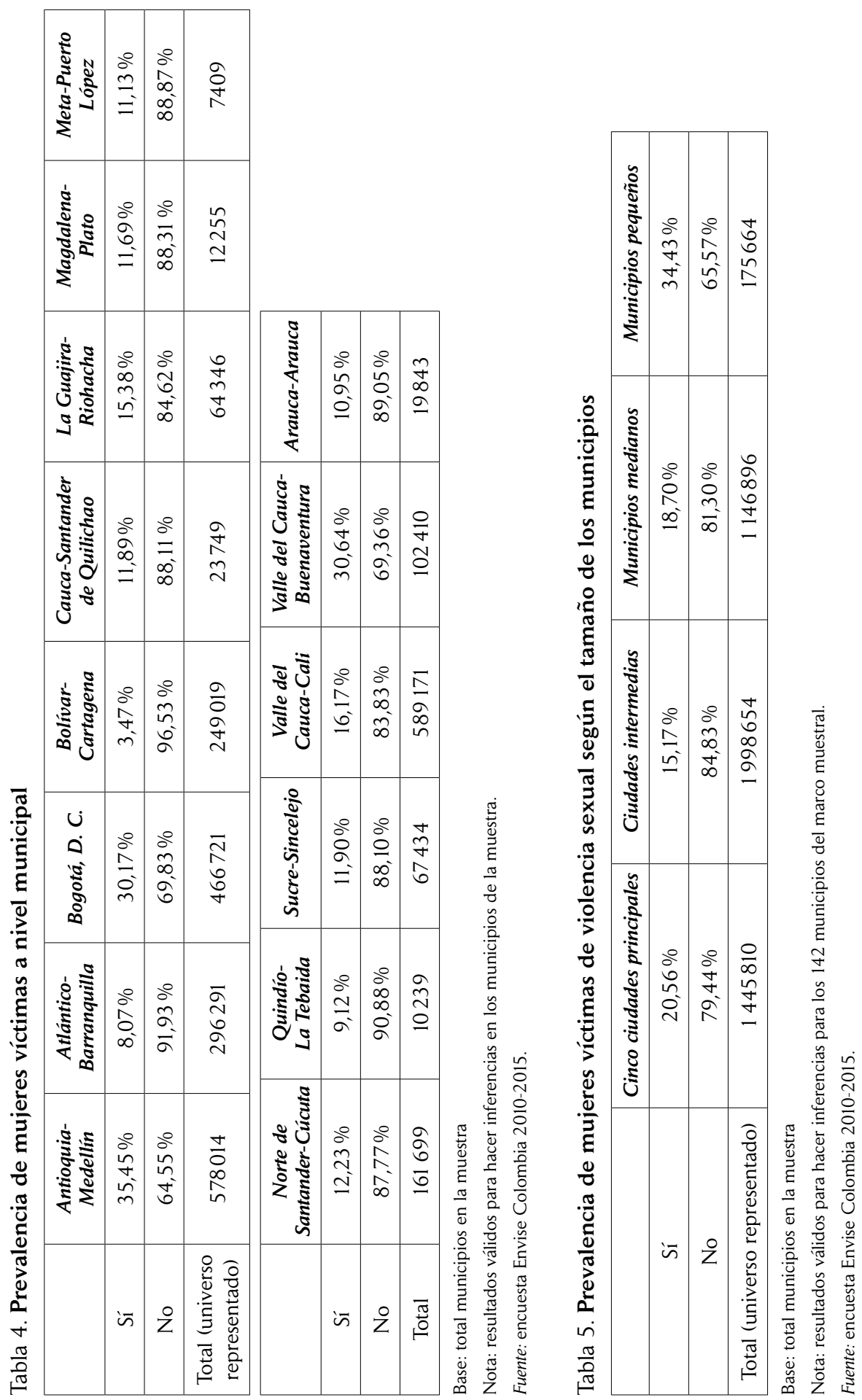

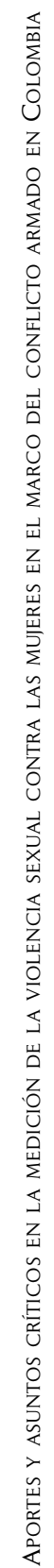


las mujeres víctimas de la violencia asociada al conflicto armado padecen una triple discriminación. Primero, por vivir principalmente en zonas periféricas que, por ser aquellas donde las instituciones del Estado son más precarias, son también las que padecen las mayores restricciones a los derechos de la población que las habitan y las que están más expuestas a la presencia de actores armados ilegales y a los riesgos del conflicto armado. ${ }^{7}$ Segundo, por ser mujeres, pues las relaciones desiguales de poder frente a los hombres las han situado en condiciones de vulnerabilidad que las exponen a riesgos específicos de género en contextos de marginalidad y violencia. A esta doble discriminación, se suman los impactos desproporcionados que el conflicto armado ha tenido sobre ellas, impactos que terminan por reforzar las vulnerabilidades específicas que las mujeres enfrentan en contextos donde no hubo conflicto armado (p. 59).

No obstante, tal como lo afirma la Casa de la Mujer (2017):

Junto a estos factores, los datos pueden conducirnos a plantear la hipótesis según la cual existen patriarcados regionales en Colombia, en la medida en que las relaciones de género y las diversas representaciones de la masculinidad dependen del contexto social, histórico y cultural. ${ }^{8}$ Así, es posible que las manifestaciones de violencia en contra de las mujeres sean contingentes a estos patriarcados regionales, $\mathrm{y}$, por lo tanto, eso podría explicar la distribución heterogénea de la violencia en el territorio, así como que ciertas mujeres o niñas presenten un mayor riesgo de ser objeto de determinadas formas de violencia debido al contexto en el que se encuentran (p. 28).

Así como lo señala Frías (2014), "la sociedad patriarcal está conformada por diversos contextos patriarcales que promueven múltiples formas y niveles de desigualdad de género" (p. 18). De acuerdo con la Casa de la Mujer (2017):

7 Esto coincide con lo señalado por García et al. (2014).

8 Frías (2008) sostiene: "La desigualdad estructural entre varones y mujeres en distintas esferas de la sociedad (económica, educativa, política y legal) genera un clima patriarcal o de desigualdad de género, lo que influye directa o indirectamente en las experiencias de violencia sexual contra las mujeres" (p. 82). 
Esta posible explicación sugiere preguntas de investigación, tales como cuáles son las características de estos patriarcados regionales y qué factores pueden influir, de manera más acentuada, en las formas y niveles específicos en que se manifiesta la violencia contra las mujeres. ${ }^{9}$ También sería interesante establecer qué efectos tiene el contexto socioeconómico y político en la configuración de estos patriarcados y qué factores históricos han contribuido a configurarlos y reproducirlos (p. 29).

Otros resultados y aportes notorios de esta encuesta tienen relación con el análisis que permite realizar de las mujeres víctimas de violencia sexual conforme con algunas características sociodemográficas, tales como el grupo étnico con el que se reconocen, el grupo etario y el estrato socioeconómico. Según el estudio realizado por la Casa de la Mujer, los datos permiten establecer la hipótesis según la cual las mujeres afrocolombianas, con edades que oscilan entre los 15 y los 24 años, que pertenecen al estrato socioeconómico 1 y que residen en municipios pequeños se encuentran más expuestas a ser víctimas de violencia sexual que las mujeres de otro origen étnico, de otros rangos de edad, de otros estratos socioeconómicos y de otros tamaños de municipio. Asimismo, la proporción de mujeres víctimas es mayor para los tipos de violencia sexual relacionados con la regulación de la vida social $(64,1 \%)$ y para el acoso sexual $(45,1 \%)$ que para los demás tipos de violencia. Por otra parte, de las mujeres que manifestaron haber sido víctimas de violencia sexual, el 16,7\% lo ha sido por violación; el 13,9\%, por servicios domésticos forzados; el 6,49\%, por aborto forzado; el 3,85\%, por prostitución forzada; el 2,68\%, por embarazo forzado; y el 1,63\%, por esterilización forzada. Las estimaciones también permiten plantear la hipótesis según la cual los tipos de violencia sexual afectan de manera

9 En esta línea de investigación, es importante tener en cuenta aportes de la antropóloga colombiana Mara Viveros, quien, entre otros temas, ha abordado las construcciones sociales de la identidad de género teniendo en cuenta contextos regionales diferentes. Asimismo, realiza comparaciones intergeneracionales y analiza la incidencia de la experiencia familiar, escolar y paraescolar en tales construcciones sociales (Viveros, 2002). Aquí tampoco se pueden soslayar los estudios pioneros de Gutiérrez de Pineda sobre la familia en Colombia, en los que planteaba la existencia de cuatro grandes complejos culturales dentro de los cuales se producen no solo, distintas formas familiares, sino también identidades masculinas heterogéneas (Gutiérrez, 1968; Rico, 2001). 
diferenciada a las mujeres teniendo en cuenta su edad. Así, las mujeres del primer rango de edad (15-24) son las principales afectadas por formas de violencia sexual relacionadas con la regulación de la vida social, el acoso sexual y el embarazo forzado. Las mujeres del segundo rango de edad (25-34) son afectadas principalmente por el aborto forzado, la prostitución forzada y la violación (Casa de la Mujer, 2017).

Tabla 6. Distribución de las mujeres víctimas según el tipo de violencia sexual

\begin{tabular}{|c|c|c|}
\hline \multicolumn{2}{|c|}{ Tipo de violencia sexual } & Porcentaje \\
\hline \multirow{4}{*}{ Regulación de la vida social } & Sí & $64,16 \%$ \\
\hline & No & $35,84 \%$ \\
\hline & Sin información & \\
\hline & Total (universo representado) & 875437 \\
\hline \multirow{4}{*}{ Servicios domésticos forzados } & Sí & $13,92 \%$ \\
\hline & No & $83,89 \%$ \\
\hline & Sin información & $2,19 \%$ \\
\hline & Total (universo representado) & 875437 \\
\hline \multirow{4}{*}{ Acoso sexual } & Sí & $45,16 \%$ \\
\hline & No & $54,76 \%$ \\
\hline & Sin información & $0,07 \%$ \\
\hline & Total (universo representado) & 875437 \\
\hline \multirow{4}{*}{ Esterilización forzada } & Sí & $1,63 \%$ \\
\hline & No & $95,58 \%$ \\
\hline & Sin información & $2,79 \%$ \\
\hline & Total (universo representado) & 875437 \\
\hline \multirow{4}{*}{ Embarazo forzado } & Sí & $2,68 \%$ \\
\hline & No & $94,53 \%$ \\
\hline & Sin información & $2,79 \%$ \\
\hline & Total (universo representado) & 875437 \\
\hline \multirow{4}{*}{ Aborto forzado } & Sí & $6,49 \%$ \\
\hline & No & $90,72 \%$ \\
\hline & Sin información & $2,79 \%$ \\
\hline & Total (universo representado) & 875437 \\
\hline
\end{tabular}




\begin{tabular}{|l|l|c|}
\hline \multicolumn{2}{|c|}{ Tipo de violencia sexual } & Porcentaje \\
\hline \multirow{4}{*}{ Prostitución forzada } & Sí & $3,85 \%$ \\
\cline { 2 - 3 } & No & $93,36 \%$ \\
\cline { 2 - 3 } & Sin información & $2,79 \%$ \\
\cline { 2 - 3 } & Total (universo representado) & 875437 \\
\hline \multirow{4}{*}{ Violación } & Sí & $16,77 \%$ \\
\cline { 2 - 3 } & No & $80,08 \%$ \\
\cline { 2 - 3 } & Sin información & $3,14 \%$ \\
\cline { 2 - 3 } & Total (universo representado) & 875437 \\
\hline \multirow{5}{*}{ Otro } & Sí & $2,01 \%$ \\
\cline { 2 - 3 } & No & $95,31 \%$ \\
\cline { 2 - 3 } & Sin información & $2,68 \%$ \\
\cline { 2 - 3 } & Total (universo representado) & 875437 \\
\hline
\end{tabular}

Base: total de encuestas realizadas

Nota: resultados válidos para hacer inferencias para los 142 municipios del marco muestral.

Fuente: elaboración de los autores con base en los resultados de la encuesta Envise Colombia 2010-2015.

Tal como puede observarse en la tabla $7:$

Un hallazgo notable de esta encuesta fue que, con excepción del acoso sexual y la esterilización forzada, cuyo principal agresor fue un no familiar, el principal agresor de las diversas formas de violencia sexual contra las mujeres fue un integrante de su propia familia. Asimismo, al observar con detalle la participación que los actores armados ilegales tuvieron, como agresores, en cada una de las formas de violencia sexual, identificamos que, con excepción de la violación, estos actores tuvieron una participación mayor, e incluso única, como perpetradores de los diversos tipos de violencia sexual contra las mujeres (Casa de la Mujer, 2017, p. 21). 


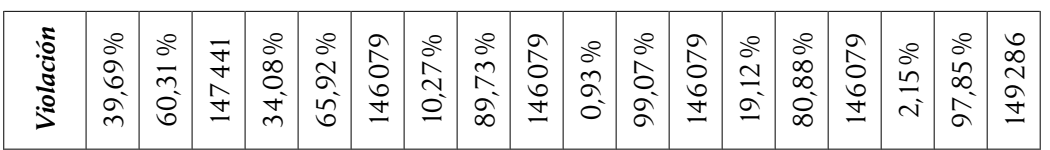

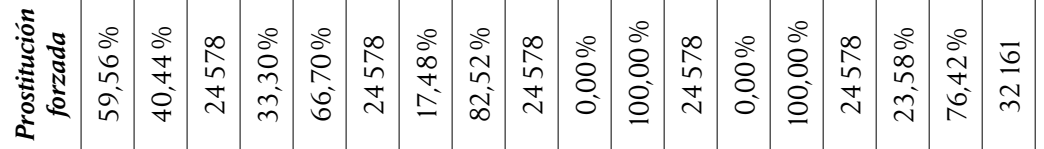

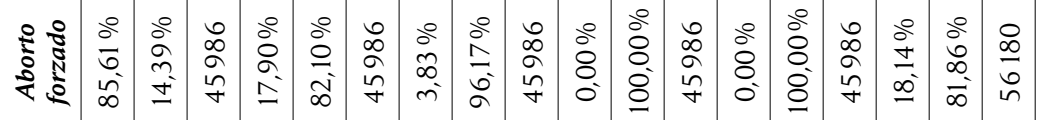

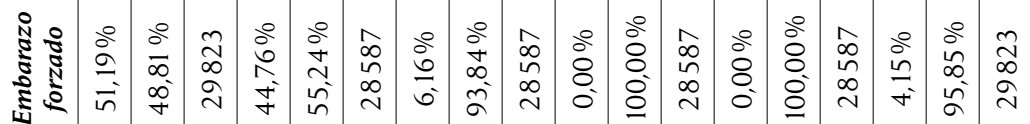

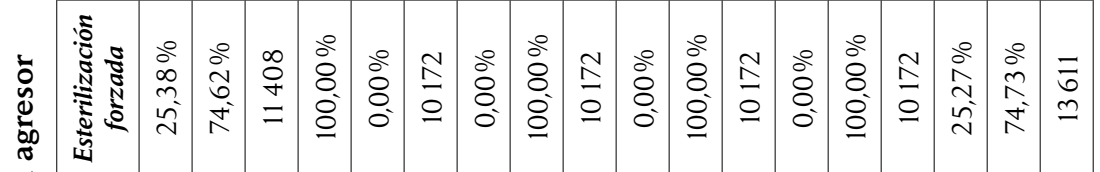

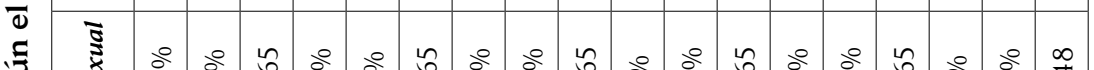

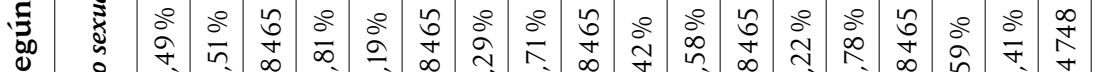

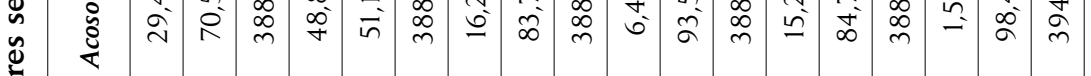

$\frac{\sqrt[d]{3}}{\mathfrak{z}}$

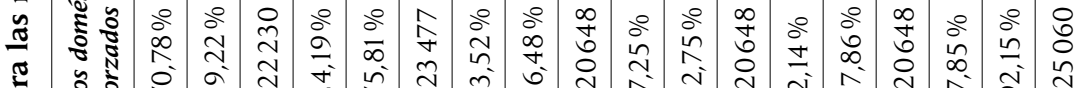

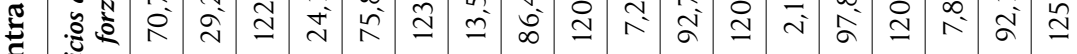

\begin{tabular}{|c|c|c|c|c|c|c|c|c|c|c|c|c|c|c|c|c|c|c|}
\hline & & & & & & & & & & & & & & & & & & \\
\hline 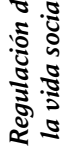 & $\begin{array}{l}0 \\
0 \\
\infty \\
\infty \\
\infty\end{array}$ & $\begin{array}{l}\stackrel{0}{a} \\
\underline{\sigma} \\
=\end{array}$ & $\frac{\infty}{\tilde{\sigma}}$ & $\begin{array}{l}\circ \\
0 \\
\text { N }\end{array}$ & 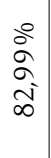 & 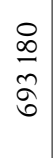 & $\begin{array}{l}8 \\
8 \\
0 \\
\infty\end{array}$ & $\begin{array}{l}0 \\
0 \\
0 \\
0 \\
1 \\
2\end{array}$ & $\frac{\infty}{\tilde{\sigma}}$ & 0 & $\begin{array}{l}8 \\
8 \\
8 \\
8\end{array}$ & $\frac{\infty}{\infty}$ & $\begin{array}{l}0 \\
i n \\
\infty \\
n\end{array}$ & $\begin{array}{l}\frac{0}{10} \\
\frac{1}{0} \\
a\end{array}$ & $\begin{array}{l}\infty \\
\frac{\infty}{n} \\
\hat{\sigma}\end{array}$ & $\begin{array}{l}0 \\
0 \\
0 \\
\infty \\
= \\
=\end{array}$ & $\begin{array}{l}2 \\
i n \\
\infty \\
\infty \\
\infty\end{array}$ & $\begin{array}{l}\infty \\
\tilde{0} \\
i n\end{array}$ \\
\hline \multirow{3}{*}{ 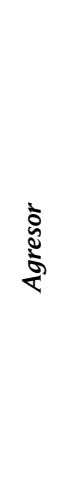 } & $\begin{array}{l}\overrightarrow{0} \\
\dot{0}\end{array}$ & $\begin{array}{l}\dot{0} \\
\dot{0}\end{array}$ & 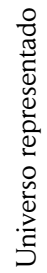 & $\dot{0}^{\dot{0}}$ & $\begin{array}{l}\dot{0} \\
\dot{0}\end{array}$ & 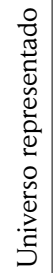 & $\overrightarrow{0}$ & $\begin{array}{l}\overrightarrow{0} \\
0\end{array}$ & 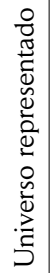 & $\begin{array}{l}\dot{0} \\
\dot{0}\end{array}$ & $\dot{0}$ & 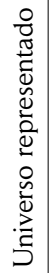 & $\overrightarrow{0}$ & $\begin{array}{c}\dot{0} \\
\dot{0}\end{array}$ & 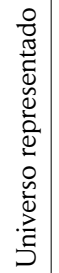 & ن & $\begin{array}{l}\dot{0} \\
\dot{0}\end{array}$ & 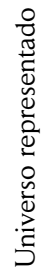 \\
\hline & $\grave{\omega}$ & ż & $\stackrel{\pi}{0}$ & $i$ & z & $\begin{array}{l}\bar{\pi} \\
0 \\
0\end{array}$ & $i n$ & Z & $\begin{array}{l}\bar{\pi} \\
0 \\
0 \\
0\end{array}$ & $i n$ & z & $\begin{array}{l}\bar{\pi} \\
0 \\
0\end{array}$ & $i n$ & z & $\begin{array}{l}\bar{\pi} \\
0 \\
0\end{array}$ & $i \bar{n}$ & $\stackrel{0}{z}$ & $\begin{array}{l}\overline{\widetilde{J}} \\
0 \\
0\end{array}$ \\
\hline & \multicolumn{3}{|c|}{ 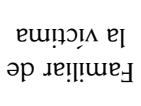 } & \multicolumn{3}{|c|}{ 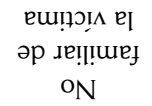 } & \multicolumn{3}{|c|}{ 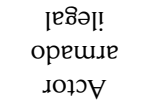 } & \multicolumn{3}{|c|}{$\begin{array}{l}\text { eว!̣qnd } \\
\text { ezıəñ }\end{array}$} & \multicolumn{3}{|c|}{ 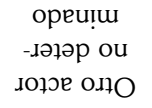 } & \multicolumn{3}{|c|}{$\begin{array}{c}\text { əpuodsəI } \\
\text { ou/əqes } \\
\text { oN }\end{array}$} \\
\hline
\end{tabular}




\section{Discusión}

Estos resultados generan un debate relevante en términos de las políticas públicas vinculadas al acceso a la justicia, la reparación y la prevención de la violencia sexual en sociedades que han atravesado por conflictos armados como el colombiano. Así, el que buena parte de las formas de violencia sexual aquí abordadas se mezclen con violencias de género plantea serias limitaciones para diferenciar los casos de violencia sexual y de género que tienen una relación directa con las dinámicas de la guerra y los que no (Centro Nacional de Memoria Histórica, 2017).

Tales limitaciones generan una discusión que resumen Céspedes et al. (2014) al preguntar:

¿Cuál es la conexión o el vínculo existente entre delito y conflicto armado, para predicar que cierta conducta delictiva es cometida como parte del conflicto? En otros términos, la línea divisoria entre la violencia propia del conflicto y aquella que más bien está atada a fenómenos de violencia intrafamiliar o delincuencia común no ha sido, ni es fácil de trazar. Si la violencia sexual está asociada al conflicto, los tipos penales que se activan son otros (delitos en persona protegida), y la investigación debe responder a un enfoque que tenga en cuenta no sólo el caso individual, sino el lugar que ese delito específico tiene en los repertorios de violencia de los grupos armados (p. 24).

En otros términos, "ubicar eventos de violencia sexual como parte del conflicto armado significa entender que su ocurrencia está atada a otra serie de hechos punibles que se dan en un momento y lugar determinados, es decir, en un contexto. Asimismo, implica comprender que ese hecho aislado puede contribuir a ciertos objetivos macro, propios del grupo armado al que pertenece el perpetrador" (Céspedes, Chaparro E Estefan, 2014, p. 27).

Por otra parte, tanto las organizaciones sociales de mujeres (Corporación Sisma Mujer, 2009) como la Corte Constitucional han argumentado que las formas de violencia sexual en las que el agresor fue un familiar de la víctima no pueden interpretarse como un fenómeno ajeno o sin ninguna relación con el contexto de conflicto armado por el 
que atraviesa la sociedad colombiana. Así, "la persistencia del conflicto se configura en el principal factor contextual que somete a las mujeres a altas probabilidades de victimización y re-victimización, especialmente asociadas a ser víctimas de violencia sexual" (Casa de la Mujer, 2017, p. 22).

En tal sentido, la Corte Constitucional en el Auto 9 de $2015^{10}$ señala que

los actos de violencia sexual en contra de las mujeres se inscriben en contextos de discriminación y violencias de género estructurales, en los que tales actos de barbarie también han sido perpetrados por actores no armados, principalmente aquellos pertenecientes a los círculos próximos de las mujeres. Asimismo, esta jurisprudencia establece que la presencia de actores armados en los municipios aumenta y concreta el riesgo de violencia sexual contra la población femenina, pese a que esta violencia no sea perpetrada por tales actores sino por los propios familiares de las mujeres (Corte Constitucional, 2015, p.19).

Por su parte, las organizaciones sociales de mujeres también han argumentado que, pese a ser los familiares de las víctimas los principales agresores, esto no está desvinculado de la dinámica del conflicto armado en la medida en que esta forma de violencia es una expresión de relaciones de opresión, subordinación e injusticia social, y es un dispositivo de poder que utiliza el sistema sociosexual patriarcal para mantener, recrear y reproducir dichas relaciones (Moser, 2001; Casa de la Mujer, 2017). Esta interpretación y explicación permite "visualizar la violencia sexual contra las mujeres en el marco del conflicto como parte de un contínuum en sus vidas y no como expresiones inconexas de rabia o pérdida de control de los varones" (Cynthia, 2004, p. 43). Así, el contínuum de las violencias en contra de las mujeres adopta diversas formas:

10 Por medio del cual se hace seguimiento a la orden segunda y tercera del Auto 92 de 2008, en lo concerniente al traslado de casos de violencia sexual a la Fiscalía General de la Nación, y a la creación e implementación de un programa de prevención del impacto de género mediante la prevención de los riesgos extraordinarios de género en el marco del conflicto armado y el Programa de Prevención de la Violencia Sexual contra la Mujer Desplazada y de Atención Integral a sus Víctimas, en el marco del seguimiento a la Sentencia T-025 de 2004 (Corte Constitucional, Sala Especial de Seguimiento, Sentencia T-025 de 2004, Auto 9 del 27 de enero de 2015). 
violencia feminicida, violencia psíquica, violaciones, trata de mujeres y niñas, prostitución forzada, esclavitud sexual, control afectivo y sexual, aborto, embarazo forzado, violencia simbólica y económica, entre otras; violencias que se exacerban en contextos de conflicto armado (Casa de la Mujer, 2017).

Estudiosas del tema como Margaret Walker coinciden con lo planteado por las organizaciones de mujeres al considerar la violencia sufrida por estas últimas en los contextos de conflicto armado como "una prolongación de la violencia que sufren a diario, o una manifestación extrema de la discriminación y desigualdad que las mujeres experimentan en época de paz" (Walker, 2009, p. 28). Para Walker, concebirla de esta manera es una base para predecir formas de violencia y de daño que es más probable que sufran las mujeres en tales contextos, y es esencial para emprender reformas sociales, institucionales y legales. Pese a esto, también indica que

esta forma de concebir la violencia sexual no logra reconocer, adecuadamente, la experiencia límite y particular de la violencia de género en el marco del conflicto armado. Si bien para efectos de la comprensión del fenómeno resulta útil el concepto del contínuum, en lo que tiene que ver con la reparación hay que hablar del discontinuo o, si se quiere, de la ruptura que representa el impacto de la violencia sexual contra las mujeres en el marco del conflicto (Walker, 2009, p. 19).

Respecto a este tema, el Centro Nacional de Memoria Histórica concibe la violencia sexual en el marco del conflicto como:

Aquella ejercida por miembros de cualquiera de los grupos armados y por la fuerza pública, en tanto que, a partir del dominio armado que detentan, practican un ejercicio vertical de poder basado en la fuerza. Además, incluyen la violencia sexual ejercida en contextos en donde las víctimas se encuentran en particular condición de vulnerabilidad por razones propias del conflicto armado como, por ejemplo, el desplazamiento. En este segundo caso, si bien no necesariamente los victimarios hacen parte de un grupo armado, aprovechan la situación de vulnerabilidad de sus víctimas para violentarlas (Centro Nacional de Memoria Histórica, 2015, p. 120). 
Esta interpretación haría necesario establecer la situación de vulnerabilidad por razones propias del conflicto de las mujeres encuestadas que afirmaron ser víctimas de violencia sexual en las que el o los victimarios no fueron actores armados, ni fuerza pública, sino familiares, para clasificarla como propia o vinculada al conflicto armado. Desde nuestro punto de vista, esto último se asocia con lo planteado por Agoff et al. (2013) respecto a la necesidad de establecer los vínculos entre un contexto marcado por formas de violencia (contexto de guerra irregular, por ejemplo) y otras formas de violencia que pueden ser promovidas, permitidas $\mathrm{o}$ simplemente "normalizadas" en tales escenarios. Allí los límites y el análisis se complejizan. Para las autoras, es relevante elaborar interrelaciones entre distintos fenómenos de violencia. Explorar, por ejemplo, el efecto en el largo plazo de la violencia sobre las dinámicas de la vida cotidiana, los cambios que conlleva en los valores o en la identificación de acciones "normales" que pueden hacer que un joven o adulto consideren "normal" violentar sexualmente a las niñas, niños y mujeres (Agoff, et al., 2013).

Los resultados de la encuesta nos permiten identificar la necesidad de abandonar el proceso de especialización y diferenciación de los distintos tipos de violencia y avanzar hacia la explicación de sus relaciones. Y en este terreno, la investigación de la violencia de género tiene mucho para aportar, porque desde hace varias décadas ha teorizado sobre las conexiones entre los diferentes tipos de violencia y sobre el vínculo entre la violencia y las grandes inequidades estructurales (Agoff, et al., 2013).

\section{Consideraciones finales}

La presente reflexión ha mostrado algunos de los retos que plantea la medición de la violencia sexual en el contexto del conflicto armado en Colombia. Si se asumen como 'casos relacionados con el conflicto' solo aquellos en los que se señalan a los actores armados como principales perpetradores, se identifica únicamente una pequeña proporción. En otras palabras, al calcular la prevalencia de esta forma de violencia incluyendo aquellos casos en los que el o los agresores de las sobrevivientes fueron integrantes de su núcleo familiar, se puede estar incurriendo en una sobreestimación del fenómeno. 
Pese a esto, la encuesta nos ofrece algunos datos interesantes respecto a las formas de violencia contra las mujeres que se manifiestan en el ámbito local. Así, la regulación de la vida social, el acoso sexual y las violaciones son el común denominador, teniendo como principales agresores a los familiares de las víctimas. Este último rasgo vuelve a sugerirnos que tales formas de violencia corresponden a eventos de violencia intrafamiliar y no a eventos relacionados con el conflicto armado. Sin embargo, parafraseando a Wood, consideramos que las críticas planteadas a los resultados arrojados por la encuesta pueden ser parte de un enfoque demasiado limitado sobre la violencia sexual asociada al conflicto, corriendo el riesgo de ignorar las características del contexto, que son fundamentales (Wood, 2016).

Así, hemos visto, en primer lugar, que los resultados de la encuesta ofrecen alguna evidencia empírica y plantean líneas de investigación para continuar indagando sobre la relación que parece existir entre la violencia sexual contra las mujeres y variables demográficas y económicas, tales como el origen racial y étnico, el grupo etario y las condiciones socioeconómicas. ${ }^{11}$ Como un hallazgo importante de la encuesta fue posible establecer que la distribución de la violencia sexual contra las mujeres en el territorio nacional es heterogénea y puede sugerir la existencia de patriarcados regionales que permiten comprender la causa de que ciertas mujeres o niñas presenten mayor riesgo de ser objeto de determinadas formas de violencia sexual en contextos específicos. Esto último nos conduce a valorar el lugar y la importancia que tienen las relaciones de género y la configuración de representaciones de la masculinidad en la explicación del fenómeno.

Por otra parte, hemos visto la relevancia de la explicación ofrecida por las organizaciones sociales de mujeres al hallazgo según el cual la mayor parte de los agresores corresponde a familiares de las víctimas. Para tales organizaciones, la violencia sexual contra las mujeres en el contexto del conflicto debe ser vista como parte de un contínuum en sus vidas y no como expresiones inconexas.

11 Estos elementos sugieren la necesidad y pertinencia de incorporar, en los estudios que se hagan sobre el tema, un enfoque interseccional que permita comprender diferentes formas de agenciamiento y discriminación, a partir de la interacción de diversos modos de subordinación, tales como los relacionados con las cuestiones de género, raza/etnia y clase (Telmo $\xi$ Pizzinato, 2019). 


\section{Referencias}

Agoff, C., Casique, I., \& Castro, R. (Coords.). (2013). Visible en todas partes. Estudios sobre violencia contra mujeres en múltiples ámbitos. México: CRIM/ UNAM-Miguel Ángel Porrúa.

Casa de la Mujer. (2010). Primera encuesta de prevalencia de violencia sexual en contra de las mujeres en el contexto del conflicto armado 2001-2009. Bogotá: Casa de la Mujer-Oxfam Intermón. Recuperado de http://www.peacewomen.org/assets/file/Resources/NGO/vaw_primeraencuestadeprevalencia_oxfam_dec2010.pdf

Casa de la Mujer. (2017). Encuesta de prevalencia de violencia sexual en contra de las mujeres en el contexto del conflicto armado colombiano 2010-2015. Bogotá: Casa de la Mujer-Oxfam Intermón.

Centro Nacional de Memoria Histórica. (2015). Crímenes que no prescriben: la violencia sexual del Bloque Vencedores de Arauca. Bogotá: CNMH.

Centro Nacional de Memoria Histórica. (2017). La guerra inscrita en el cuerpo. Informe nacional de violencia sexual en el conflicto armado. Bogotá: $\mathrm{CNMH}$.

Céspedes, L., Chaparro, N., \& Estefan, S. (2014). Metodologías en el estudio de la violencia sexual en el marco del conflicto armado. Colombia Internacional, (80), 19-56. Recuperado de http://www.scielo.org.co/pdf/rci/n80/ n80a02.pdf

Colombia, Corte Constitucional, Sala Especial de Seguimiento, Sentencia T-025 de 2004, Auto 9 del 27 de enero de 2015, magistrado ponente: L. E. Vargas Silva.

Corporación Humanas. (2009). Situación en Colombia de la violencia sexual contra las mujeres. Bogotá: Ediciones Antropos. Recuperado de http://www. bdigital.unal.edu.co/45588/1/9789589782163.pdf

Corporación Sisma Mujer. (2008). Arañando la justicia: violencia sexual e impunidad en el conflicto armado en Colombia. Bogotá. Recuperado de http://www. sismamujer.org/node/46.htm

Corporación Sisma Mujer. (2009). Mujeres en conflicto: violencia sexual y paramilitarismo. Bogotá. Recuperado de http://www.sismamujer.org/node/69.htm Cynthia, C. (2004). The continuum of violence: a gender perspective on war and peace. In W. Giles \& J. Hyndman (Eds.), Sites of violence: gender and conflict zones (pp. 24-44). Berkeley-Los Angeles, CA: University of California Press.

Echeverri, J. (2002). La violencia sexual como arma de guerra frente al derecho internacional humanitario (Tesis de pregrado en Derecho, Facultad de Ciencias Jurídicas, Pontificia Universidad Javeriana). 
Fileborn, B. (2013). Conceptual understandings and prevalence of sexual harassment and street harassment. Melbourne: Australian Institute of Family Studies.

Françoise, R., Guberek, T., E Hoover, A. (2011). El uso de datos cuantitativos para entender la violencia sexual relacionada con el conflicto armado colombiano: retos y oportunidades. Bogotá: Editorial Corporación Punto de Vista-Benetech Technology Saving Humanity. Recuperado de https://hrdag.org/wp-content/ uploads/2013/01/CPV-Benetech-estudioVS-abril-2011.pdf

Frías, S. (2008). Diferencias regionales en la prevalencia de la violencia doméstica en México: la influencia de la estructura patriarcal. En R. Castro \& I. Casique (Eds.), Estudios sobre cultura, género y violencia contra las mujeres (pp. 81-138). México: Centro Regional de Investigaciones Multidisciplinarias, UNAM.

Frías, S. (2014). Ámbitos y formas de violencia contra mujeres y niñas: evidencias a partir de las encuestas. Acta Sociológica, 65, 11-36. Doi: https://doi. org/10.1016/S0186-6028(14)70235-X

García, V. M., E Espinosa, J. R. (2014). El derecho al Estado: los efectos legales del apartheid institucional en Colombia. Bogotá, D.C.: Dejusticia. Recuperado de http://www.dejusticia.org/files/r2_actividades_recursos/fi_name_recurso.361.pdf

González, M., E Valdez, S. (2008). Violencia hacia las mujeres en ocho regiones indígenas de México: notas metodológicas en torno a la Encuesta Nacional sobre Salud y Derechos de las Mujeres Indígenas (Ensademi), 2007. Estudios Sociológicos, XXVI(77), 435-450.

Gutiérrez, V. (1968). Familia y cultura en Colombia. Tipologías, funciones y dinámica de la familia. Manifestaciones múltiples a través del mosaico cultural y sus estructuras sociales. Bogotá: Tercer Mundo-Departamento de Sociología, Universidad Nacional de Colombia.

Moser, C. (2001). The gendered continuum of violence and conflict: an operational framework. In C. Moser E F. Clark (Eds.), Victims, perpetrators or actors? Gender, armed conflict and political violence. New York: Plagrave.

Otero, S., Quintero, V., E Bolívar, I. J. (2009). Las barreras invisibles del registro de la violencia sexual en el conflicto armado colombiano. En Forensis: datos para la vida 2009 (pp. 334-354).

Oxfam Colombia. (2009). La violencia sexual en Colombia: un arma de guerra. Recuperado de http://www.colombiassh.org/site/spip.php?article468 Rico, A. (2001). Virginia Gutiérrez de Pineda. Revista Colombiana de Sociología, VI(1), 41-48.

Sánchez, G. (2010). ¿Será que a las mujeres nos matan porque nos aman? Feminicidios en Colombia 2002-2009. Bogotá: G2 Editores. 
Sanchis, E. (2011). Prostitución voluntaria o forzada. Una contribución al debate. Papers. Revista de Sociología, 96(3), 915-936. Doi: https://doi.org/10.5565/ rev/papers/v96n3.121

Slaughter, L. (2009). Sexual assault. In J. A. Marx (Ed.), Rosen's emergency medicine: concepts and clinical practice ( $7^{\text {th }}$ ed.) (Chap. 64). Philadelphia, PA: Mosby Elsevier.

Telmo Romano, A. Q., G Pizzinato, A. (2019). Migração de mulheres para o Brasil: interseções de gênero, raça/etnia e classe. Trabajo Social, 21 (2), 197213. Doi: https://doi.org/10.15446/ts.v21n2.75072

Valdez, R. (2004). Del silencio privado a las agendas públicas: el devenir de Ia lucha contra la violencia doméstica en México. En M. Torres (Comp.), Violencia contra las mujeres en contextos urbanos y rurales (pp. 417-447). México: El Colegio de México.

Viveros, M. (2002). De quebradores y cumplidores. Ser hombres, masculinidades y relaciones de género en Colombia. Bogotá, D.C: CEs-Universidad Nacional de Colombia-Fundación Ford-Profamilia.

Walker, M. (2009). Gender and violence in focus: a background for gender justice in reparations. En R. Marín-Rubio (Ed.), The gender of reparations. Unsettling sexual hierarchies while redressing human rights violations (pp. 1862). New York: Cambridge University Press.

Wood, E. J. (2009). Armed groups and sexual violence: when is wartime rape rare? Politics and Society, 37(1), 131-161.

Wood, E. J. (2009a). Violencia sexual durante la guerra: hacia un entendimiento de la variación. Análisis Político, 66, 3-27.

Wood, E. J. (2016). La violencia sexual asociada al conflicto y las implicaciones políticas de investigaciones recientes. Estudios Socio-Jurídicos, 18(2), 13-46. Doi: https://doi.org/10.12804/esj 18.02.2016.01

World Health Organization. (1999). Putting women's safety first: ethical and safety recommendations for research on domestic violence against women. Report $\mathrm{N}^{\circ}$ WHO/EIP/GPE/99.2. Geneva: Global Programme on Evidence for Health Policy, World Health Organization. 